American Journal of Applied Sciences 9 (8): 1273-1282, 2012

ISSN 1546-9239

(C) 2012 Science Publications

\title{
Evaluation of the Stability of Underground Rock Pillars through a Probabilistic Approach
}

\author{
${ }^{1}$ Massimo Guarascio and ${ }^{2}$ Pierpaolo Oreste \\ ${ }^{1}$ Department of Chemistry, Materials and Environmental Engineering (DICMA), \\ Faculty of Engineering, University of Rome La Sapienza, via Eudossiana 18, 00184 Rome, Italy \\ ${ }^{2}$ Department of Environmental, Land and Infrastructural Engineering (DIATI), \\ Faculty of Engineering, Politecnico di Torino, corso Duca degli Abruzzi 24, 10129 Turin, Italy
}

\begin{abstract}
Problem statement: When the room and pillar mining method is adopted, the dimensioning of the rock pillars is one of the most important aspects that need to be faced from the engineering point of view. The available calculation methods are usually simplified and involve the areas of influence method for the evaluation of the mean axial stress induced in the pillar and the empirical formula to estimate the global strength of the pillar. Approach: A new probabilistic approach is proposed in this study concerning the evaluation of the degree of safety of a pillar, as far as rupture of the rock is concerned. This approach is based on the exact evaluation of the stress state inside the pillar and it takes into due consideration the typical uncertainty of the geomechanical parameters of the rock mass that makes up the pillar. Results and Conclusion: The pillar can therefore be dimensioned through an analysis of the cumulative probability distribution of the point safety factor in one or more points inside it.
\end{abstract}

Key words: Finite Element Methods (FEM), Finite Difference Methods (DFM), geomechanical parameters, pillar mining method, cumulative probability distribution

\section{INTRODUCTION}

The determination of the safety degree of an underground rock pillar during room and pillar mining is one of the most interesting problems of rock engineering and rock mechanics and is also one of the most frequently studied ones. The correct dimensioning of a rock pillar should in fact guarantee safety, as far as stability is concerned, in order to avoid the detachment of portions of rock from the pillar itself, or even its total collapse, which would result in very serious consequences for the personnel working underground and create problems for the continuation of the underground works (Oreste, 2008; Sadrnejad, 2006).

The stress induced in pillars has usually been estimated by the area of influence method, for the sake of simplicity. This method allows the mean axial stress of the pillar section to be determined and the efforts of scholars have therefore been concentrated on defining a mean rupture stress (strength) of a pillar in function of the type of rock, the dimensions and the shape of the pillar itself.

The relationship of the two values (the strength of the pillar divided by the mean induced axial stress) leads to the definition of the global safety factor of the pillar, which is then used for its dimensioning.

The simplistic area of influence method can today be considered inadequate as an instrument for the dimensioning of rock pillars through a single global value of the safety factor: more sophisticated calculation methods that can indicate the stress conditions at each point inside the pillar and which can therefore determine the value of point safety factors in the rock mass that makes up the pillar, are therefore necessary.

Moreover, the uncertainty of the exact knowledge of the characteristics of a rock mass makes the use of a probabilistic type approach necessary, in particular as far as the strength values are concerned. The data obtained from a geomechanical characterisation (A'ssim and Xing, 2010) should in fact be considered as an estimation that can sometimes have a high degree of uncertainty. Apart from this, the definition of the strength of the rock mass, on the basis of data from laboratory and/or in situ tests (Jamaludin et al., 2006; Huat, 2005), is usually made on the basis of empirical type correlations that always have a certain degree of reliability.

Corresponding Author: Massimo Guarascio, Department of Chemistry, Materials and Environmental Engineering (DICMA), Faculty of Engineering, University of Rome La Sapienza, via Eudossiana 18, 00184 Rome, Italy 
An efficient way of working should therefore not only involve a point evaluation of the stress state inside the pillar, but should also adopt a probabilistic approach (Oreste, 2005a; 2005b; 2006) in order to be able to correctly represent the strength characteristics of the rock mass that makes up the pillar.

The dimensioning of the pillars should therefore not be based on deterministic values of the safety factor, but on the probabilistic distribution of the point safety factors inside the pillar, which are able to offer better indications on the degree of safety of the pillar and on the reliability of the obtained evaluations.

A probabilistic analysis technique of the distribution of the safety factors inside a pillar is illustrated in this work. This technique is based on the knowledge of the tri-dimensional stress state inside the pillar and on the strength characteristics of the rock, which are known with a certain degree of uncertainty.

\section{MATERIALS AND METHODS}

Analyses of the stress state in a pillar: The stress state inside a pillar can be calculated with a high degree of precision through the use of tri-dimensional numerical modelling (Fig. 1). Finite Element Methods (FEM) or Finite Difference Methods (DFM) is usually used for this purpose.

The calculation gives the complete stress state, composed of six stress values (three normal stress values and three shear stress values): $\sigma_{\mathrm{x}}, \sigma_{\mathrm{y}}, \sigma_{\mathrm{z}}, \tau_{\mathrm{xy}}$, $\tau_{\mathrm{xz}}, \tau_{\mathrm{yz}}$ for each numerical element of the model (Fig. 2 ). It is possible to determine the principal stresses and, in particular, the maximum principal stress $\left(\sigma_{\max }\right.$ $\left.=\sigma_{1}\right)$ and minimum principal stress $\left(\sigma_{\min }=\sigma_{3}\right)$ from these six stresses (Fig. 3). The maximum and minimum principal stresses are of great interest for the evaluation of the degree of safety of the rock, as far as its rupture is concerned.

The principal stresses are obtained by resolving the following third degree equation:

$$
\sigma^{3}-I_{1} \cdot \sigma^{2}+I_{2} \cdot \sigma-I_{3}=0
$$

Where:

$$
\begin{aligned}
& \mathrm{I}_{1}=\sigma_{\mathrm{x}}+\sigma_{\mathrm{y}}+\sigma_{\mathrm{z}} \\
& \mathrm{I}_{2}=\sigma_{\mathrm{x}} \cdot \sigma_{\mathrm{y}}+\sigma_{\mathrm{x}} \cdot \\
& \sigma_{\mathrm{z}}+\sigma_{\mathrm{y}} \cdot \sigma_{\mathrm{z}}-\tau_{\mathrm{xy}}^{2}-\tau_{\mathrm{xz}}^{2}-\tau_{\mathrm{yz}}^{2} \\
& \mathrm{I}_{3}=\sigma_{\mathrm{x}} \cdot \sigma_{\mathrm{y}} \cdot \sigma_{\mathrm{z}}+2 \cdot \tau_{\mathrm{xy}} \cdot \tau_{\mathrm{xz}} \cdot \tau_{\mathrm{yz}} \\
& -\sigma_{\mathrm{x}} \cdot \tau_{\mathrm{yz}}^{2}-\sigma_{\mathrm{y}} \cdot \tau_{\mathrm{xz}}^{2}-\sigma_{\mathrm{z}} \cdot \tau_{\mathrm{xy}}^{2}
\end{aligned}
$$

If the solution is unique (the three principal stresses are equal):

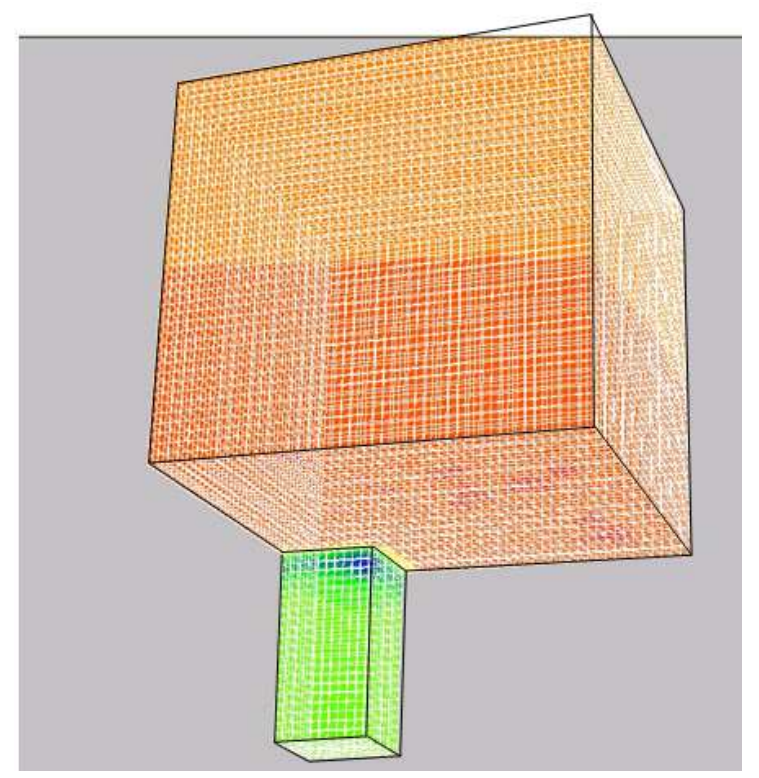

Fig. 1: Representation of the geometry of a tridimensional numerical model. Thanks to the symmetry of the model, only $1 / 8$ of the pillar ( $1 / 4$ of its upper portion) is represented directly in the model together with $1 / 4$ of the rock on the roof of the mining rooms

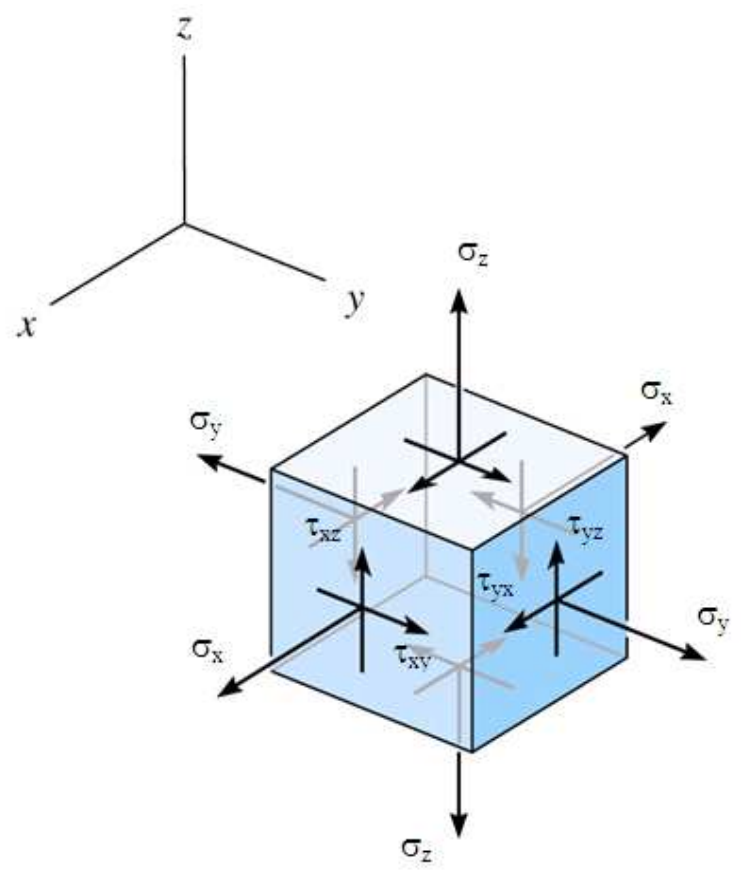

Fig. 2: Complete tri-dimensional stress state obtained from the calculation for each numerical element of the model 


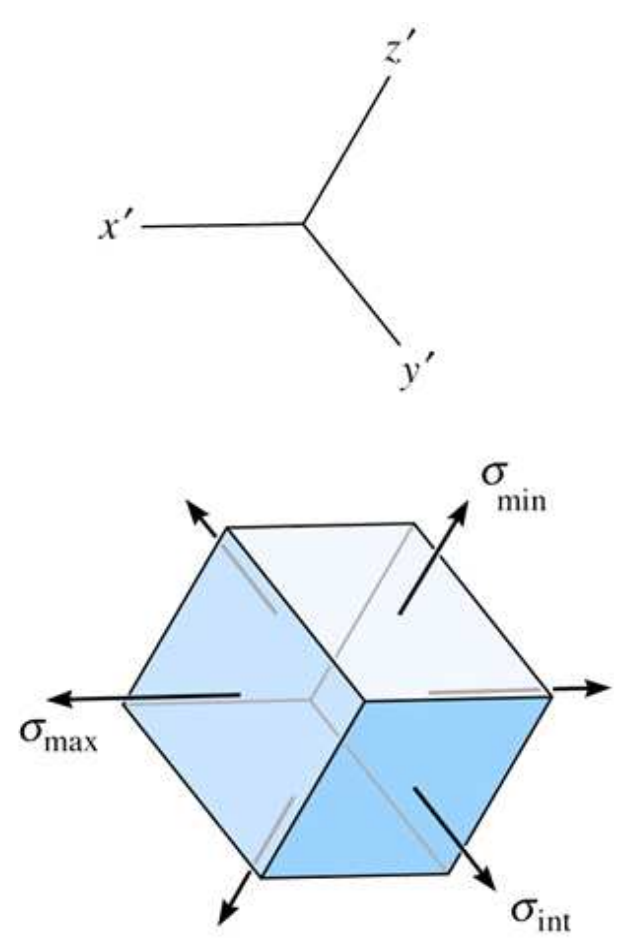

Fig. 3:Determination of the three principal stresses (maximum: $\sigma_{\max }$; intermediate: $\sigma_{\text {int }}$; minimum: $\left.\sigma_{\min }\right)$ on the basis of the complete knowledge of the stress state in a numerical element

$\mathrm{I}_{2}=\frac{1}{3} \cdot \mathrm{I}_{1}^{2} \quad$ e $\quad \mathrm{I}_{3}=\frac{1}{9} \cdot \mathrm{I}_{1}^{3}$ and the principal stresses are equal to $\sigma_{1,2,3}=\sqrt[3]{\mathrm{I}_{3}}$

If two of the principal stresses are equal:

$$
\begin{aligned}
& {\left[\frac{1}{9} \cdot\left(3 \cdot I_{2}-I_{1}^{2}\right)\right]^{3}+} \\
& {\left[-\frac{1}{27} \cdot I_{1}^{3}+\frac{1}{6} \cdot I_{1} \cdot I_{2}-\frac{1}{2} \cdot I_{3}\right]^{2}=0}
\end{aligned}
$$

and the principal stresses are equal to:

$$
\begin{aligned}
& \sigma_{1}=2 \cdot \sqrt[3]{\frac{1}{27} \cdot I_{1}^{3}-\frac{1}{6} \cdot I_{1} \cdot I_{2}+\frac{1}{2} \cdot I_{3}}+\frac{1}{3} \cdot I_{1} \\
& \sigma_{2,3}=-\sqrt[3]{\frac{1}{27} \cdot I_{1}^{3}-\frac{1}{6} \cdot I_{1} \cdot I_{2}+\frac{1}{2} \cdot I_{3}}+\frac{1}{3} \cdot I_{1}
\end{aligned}
$$

Otherwise (the three principal stresses are different from each other):

$$
\begin{aligned}
& \sigma_{1}=2 \cdot \sqrt{\left|\frac{1}{9} \cdot\left(3 \cdot I_{2}-I_{1}^{2}\right)\right|} \cdot \cos \frac{\varphi}{3}+\frac{1}{3} \cdot I_{1} \\
& \sigma_{2,3}=-2 \cdot \sqrt{\left|\frac{1}{9} \cdot\left(3 \cdot I_{2}-I_{1}^{2}\right)\right|} \cdot \cos \left(\frac{\varphi}{3} \pm \frac{\pi}{3}\right)+\frac{1}{3} \cdot I_{1}
\end{aligned}
$$

Where:

$$
\varphi=\arccos \left(\frac{\frac{1}{27} \cdot I_{1}^{3}-\frac{1}{6} \cdot I_{1} \cdot I_{2}+\frac{1}{2} \cdot I_{3}}{\left(\left|\frac{1}{9} \cdot\left(3 \cdot I_{2}-I_{1}^{2}\right)\right|\right)^{\frac{3}{2}}}\right)
$$

\section{RESULTS}

The numerical calculation of a rock pillar for a case history: The numerical calculation of a pillar in gypsum in an underground mine close to Turin (Italy) has been carried out as an example.

The mining method that is adopted is the systematic room and pillar method with regular arrangement of the pillars and mining of the rock with explosives. The underground pillars have plain dimensions of $7.5 \times 7.5 \mathrm{~m}$. The width of the room is also equal to about $7.5 \mathrm{~m}$. The pillars are $7 \mathrm{~m}$ high. The lithostatic stress state $\sigma_{\mathrm{v} 0}^{\prime}$ at the mining level is equal to $0.475 \mathrm{MPa}$.

The geomechanical characterisation of the rock mass has suggested variable results in the different zones of the deposit. The mean values obtained from the most representative parameters are:

GSI $=($ Geological Strength Index $): 73$

$\sigma_{\mathrm{ci}}=$ (uniaxial compressive strength of the intact rock): $14 \mathrm{MPa}$

$\mathrm{m}_{\mathrm{i}}=($ Hoek and Brown constant for intact rock $): 13$

The dispersion of the data obtained from both laboratory and in situ tests, above all those concerning $\sigma_{\mathrm{ci}}$, is very high and the indicated mean values are therefore poorly representative, if taken individually. For this reason, a probabilistic approach was adopted to characterise the rock mass. A Gaussian probabilistic distribution (normal distribution) was hypothesised for each of the three aforementioned parameters. The following values of the standard deviation have been obtained from the many results of the laboratory tests on intact rock and from the in situ surveys:

$\sigma_{\mathrm{GSI}}: 2, \sigma_{\sigma \mathrm{\sigma ci}}: 1 \mathrm{MPa}, \sigma_{\mathrm{mi}}: 0.5$ 
Given the symmetry of the problem, only $1 / 8$ of the pillar ( $1 / 4$ of upper part) and $1 / 4$ of the rock on the roof of the rooms have been represented directly in the numerical model (Fig. 1). The FLA-3D calculation method, which adopts a finite difference approach, was used (Itasca, 2006).

Gravity acceleration was not inserted into the calculation as the hypothesis of deep voids was made, due to the fact that the variations in the lithostatic stress in the excavation area are negligible compared to its mean value. This hypothesis is generally considered valid when the depth of the voids is greater than 4-5 times their equivalent diameter.

The lithostatic stress state was therefore applied to the upper edge of the model and kept constant for all the elements.

The edges of the model are all artificial:

- The lower edge is horizontal and passes through the mid height point of the pillar, in order to represent only the upper portion of the pillar in the model

- The four lateral edges are vertical and perpendicular to each other; they are four symmetry planes: the first two pass through the median of the square section of the pillar and the other two pass through the medium of the mining rooms

- The upper edge is the only one that is not constrained to the perpendicular movements and it is positioned at a certain distance from the top of the pillar (twice the mid-height of the pillar) so that its presence does not disturb the development of the stresses and strains inside the pillar to any great extent

The rock mass has been considered to have linear, elastic behaviour throughout the numerical model, with the same mechanical properties for both the rock that makes up the pillar and for the rock that constitutes the roof of the mining room. In this way, the value of the elastic modulus of the rock does not influence the stress state in the pillar.

The Poisson ratio $\mathrm{v}$ of the rock has been taken equal to 0.33 and an edometric value has been hypothesised for the natural lateral thrust coefficient $\mathrm{k}$ which depends on the Poisson ratio $(\mathrm{k}=0.5)$.

Since the numerical model is only made up of linear-elastic behaviour elements, the stresses induced in the rock are linearly dependent on the vertical stress applied to the upper edge of the numerical model, which has conventionally been taken equal to $1 \mathrm{MPa}$.

All the used numerical elements are cubic in shape with sides of $0.25 \mathrm{~m}$. follows:

The hypothesised calculation steps were as

- Setting up of the numerical model

- Definition of the stress-strain law of the rock

- Attribution of the mechanical properties of the rock

- Definition of the boundary conditions

- Initialization of the lithostatic stresses

- Annulment of the displacements and of the nodal velocities

- Simulation of the excavation of the room, annulling the numerical elements around the rock pillar

The pillar elements were arranged on 9 horizontal alignments belonging to three different levels: the first three alignments (1-3) were arranged on a level (level 1) close to the lower edge of the model (at mid-height of the pillar), the last three (7-9) on a level (level 3) close to the pillar-room roof connection zone (summit portion of the pillar) and the three intermediate alignments (4-6) were arranged on an intermediate level (level 2) between the two previous ones. The three alignments were arranged at each level in the following way: one central, passing close to the pillar axis (alignments 1, 4 and 7), one peripheral, passing close to the lateral edge of the pillar (alignments 3, 6 and 9) and the third one between the other two (2, 5 and 8) (Fig. 4).

The results of the calculation on the 9 alignments indicated in Fig. 4 are reported in Fig. 5 and 6, in principal stress terms. The $\sigma_{1}^{\prime} / \sigma_{\mathrm{p}}^{\prime}$ or $\sigma_{3}^{\prime} / \sigma_{\mathrm{p}}^{\prime}$ ratio, that is, the value of the maximum or minimum principal stress, scaled according to the mean axial stress in the pillar $\left(\sigma_{p}^{\prime}\right)$, is indicated on the ordinate of the graphs.

For square section pillars and with a square mesh layout, we obtain:

$$
\sigma_{\mathrm{p}}^{\prime}=\sigma_{\mathrm{v} 0}^{\prime} \cdot \frac{\left(\mathrm{w}_{\mathrm{p}}+\mathrm{l}\right)^{2}}{\mathrm{w}_{\mathrm{p}}^{2}}
$$

Where:

$\sigma_{\mathrm{p}}^{\prime}=$ Mean vertical stress in the pillar

$\sigma_{v 0}^{\prime}=$ Lithostatic vertical stress at the depth of the chamber roof

$\mathrm{w}_{\mathrm{p}}=$ Width of the pillar

1 = Width of the chamber (same value in the two horizontal directions $\mathrm{x}$ and $\mathrm{y}$ ) 
Am. J. Applied Sci., 9 (8): 1273-1282, 2012

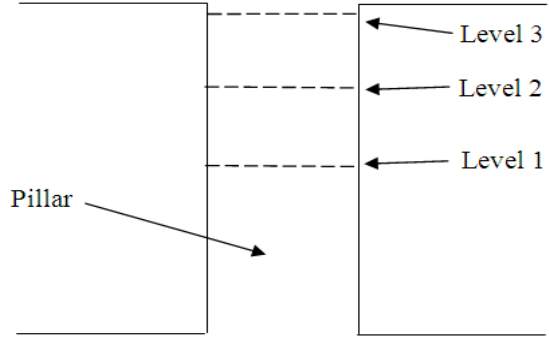

Vertical section

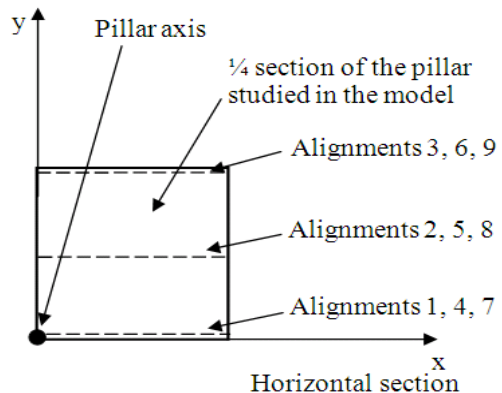

Horizontal section

Fig. 4: Position of the nine alignments considered inside the pillar

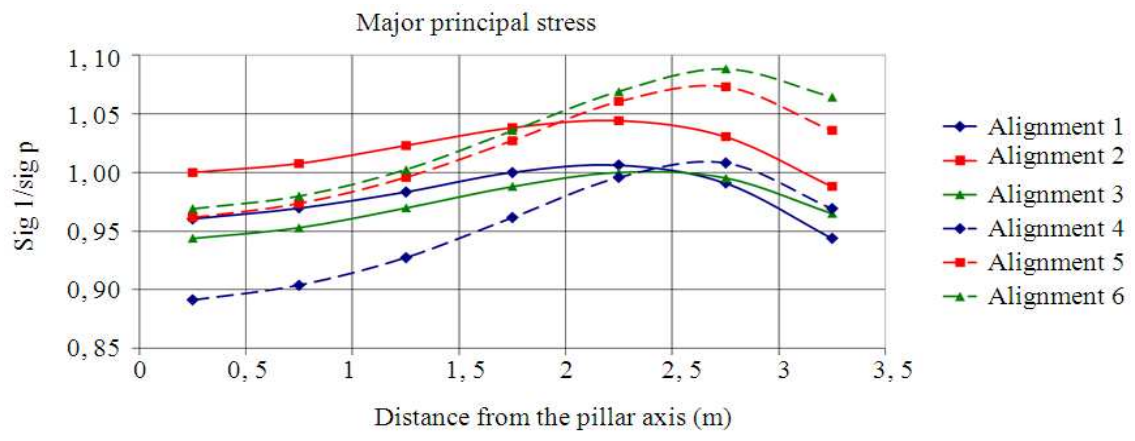

Fig. 5: Trend of the major principal stress along alignments 1-6

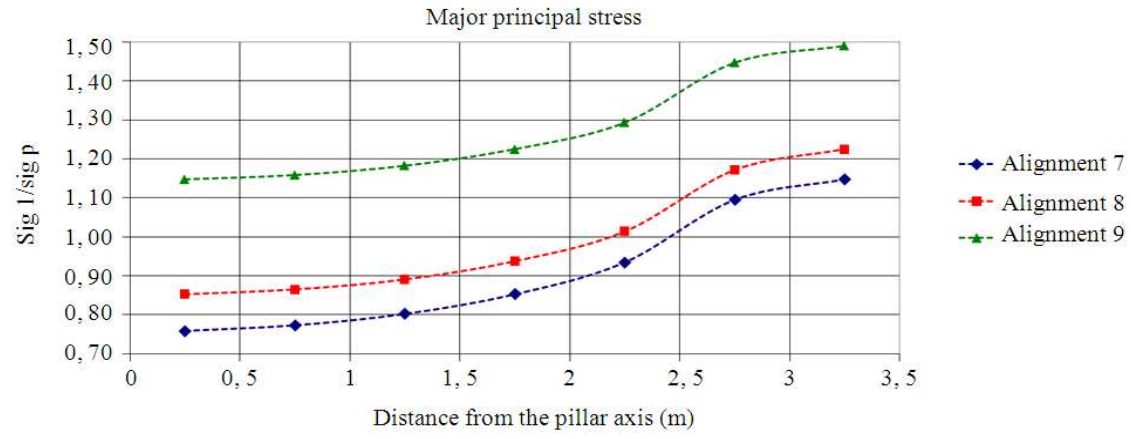

Fig. 6: Trend of the major principal stresses along alignments 7-9

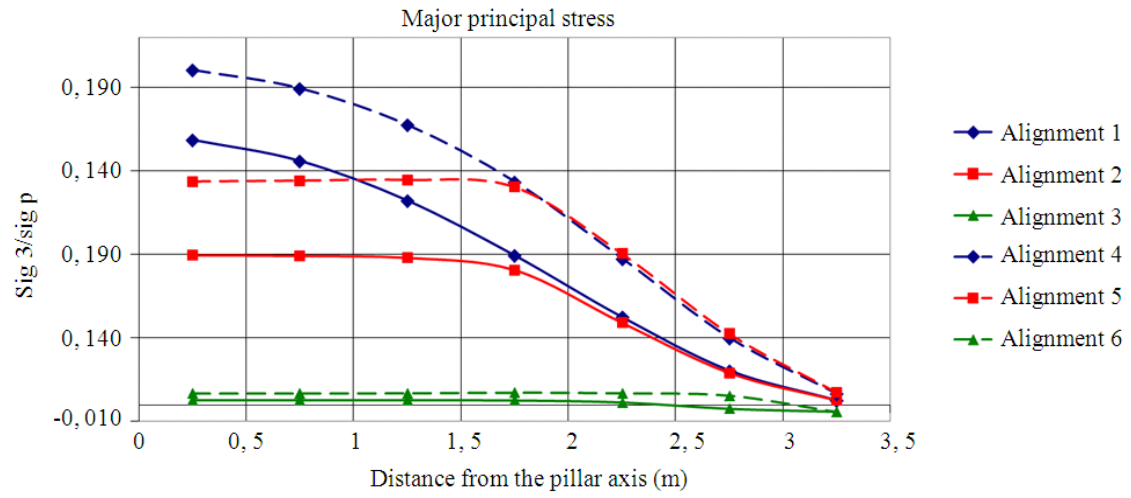

Fig. 7: Trend of the minor principal stresses along alignments 1-6 


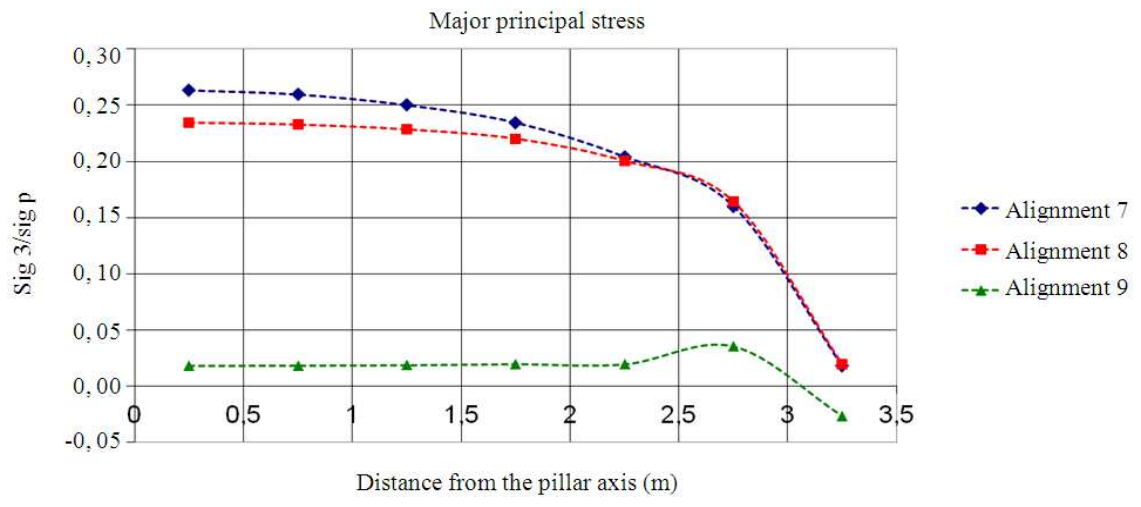

Fig. 8: Trend of the minor principal stresses along alignments 7-9

From an analysis of Fig. 5-6, it is possible to note how the major principal stresses at mid-height of the pillar (alignments 1-3) reach a value, in the portion close to the pillar axis, of about 0.96 times the mean vertical stress $\sigma_{\mathrm{p}}^{\prime}$, a value of $0.95 \cdot \sigma_{\mathrm{p}}^{\prime}$ at half of one of its sides and a value of about $0.96 \cdot \sigma_{\mathrm{p}}^{\prime}$ in the corners. At a height of $3 / 4 \cdot \mathrm{hp}$ (that is, at a distance of $1 / 4 \cdot \mathrm{hp}$ from the top of the pillar, alignments 4-6), the major principal stress in the zone close to the pillar axis has a value of about $0.89 \cdot \sigma_{\mathrm{p}}^{\prime}$; this stress increases at mid-height of the side $\left(0.97 \cdot \sigma_{p}^{\prime}\right)$ and rises to $1.06 \cdot \sigma_{\mathrm{p}}^{\prime}$ in the corner. Finally, the major principal stress close to the pillar axis is very low (about $0.76 \cdot \sigma_{\mathrm{p}}^{\prime}$ ) at the summit of the pillar (at a distance of about 1/8.hp from the roof, alignments 7-9), while it grows considerably moving towards the peripheral zones of the pillar: $1.14 \cdot \sigma_{\mathrm{p}}^{\prime}$ at half the side and $1.49 \cdot \sigma_{\mathrm{p}}^{\prime}$ in the corner.

The minor principal stresses are reported in Fig. 78: From an examination of the figures, it emerges that there is a non negligible confinement stress state in a central portion of the pillar section, with a tendency to reduce rapidly towards the edges of the pillar, where the confinement stress is cancelled out. The maximum value of the minimum principal stress at mid-height of the pillar can be found in correspondence to the pillar axis, where it reaches a value of $0.16 \cdot \sigma_{p}^{\prime}$.

The minor principal stresses in the summit portion of the pillar (at a distance of about $1 / 8 \cdot \mathrm{h}_{\mathrm{p}}$ from the roof), are very large (reaching values of $0.26 \cdot \sigma_{\mathrm{p}}^{\prime}$ ) and they rapidly reduce to zero in the cortical zone.

\section{DISCUSSION}

Evaluation of the point safety factors through a probabilistic approach: When the stress state of each point of a pillar is available, it is necessary to proceed with a comparison between such a value and the strength of the rock mass in the same points in order to be able to obtain the trend of the local safety factor inside the pillar.

The strength of the rock mass is generally known referring to correlations that are well known in the literature and which are valid for each application context.

The evaluation of the strength of a rock mass is currently usually determined by means of the Hoek and Brown (1982; 1997) strength criterion (Hoek et al., 2002) on the basis of the GSI geomechanical quality index (Hoek and Brown, 1997; Cai et al., 2004):

$$
\sigma_{1, \text { str }}^{\prime}=\sigma_{3}^{\prime}+\sigma_{\mathrm{ci}}^{\prime} \cdot\left(\mathrm{m}_{\mathrm{b}} \cdot \frac{\sigma_{3}^{\prime}}{\sigma_{\mathrm{ci}}^{\prime}}+\mathrm{s}\right)^{\mathrm{a}}
$$

where, $\sigma_{1, \text { str }}^{\prime}$ is the strength of the rock mass in the presence of the lateral confinement stress $\sigma_{3}^{\prime} ; \mathrm{m}_{\mathrm{b}}$ and $\mathrm{s}$ are the strength parameters from the Hoek and Brown strength criterion:

$$
\begin{aligned}
& \mathrm{m}_{\mathrm{b}}=\mathrm{m}_{\mathrm{i}} \cdot \mathrm{e}^{\frac{\mathrm{GSI}-100}{28}} \\
& \mathrm{~s}=\mathrm{e}^{\frac{\mathrm{GSI}-100}{9}} \\
& \mathrm{a}=\frac{1}{2}+\frac{1}{6} \cdot\left(\mathrm{e}^{-\frac{\mathrm{GSI}}{15}}-\mathrm{e}^{-\frac{20}{3}}\right)
\end{aligned}
$$

$\mathrm{m}_{\mathrm{i}}$ is a coefficient that is obtained from triaxial load tests on rock samples in the laboratory and it is possible to estimate it, as a first approximation, in function of the type of rock (Hoek and Brown, 1997); $\sigma_{\mathrm{ci}}^{\prime}$ is the uniaxial compressive strength of the intact rock measured in the laboratory on cylindrical rock samples. 
Am. J. Applied Sci., 9 (8): 1273-1282, 2012

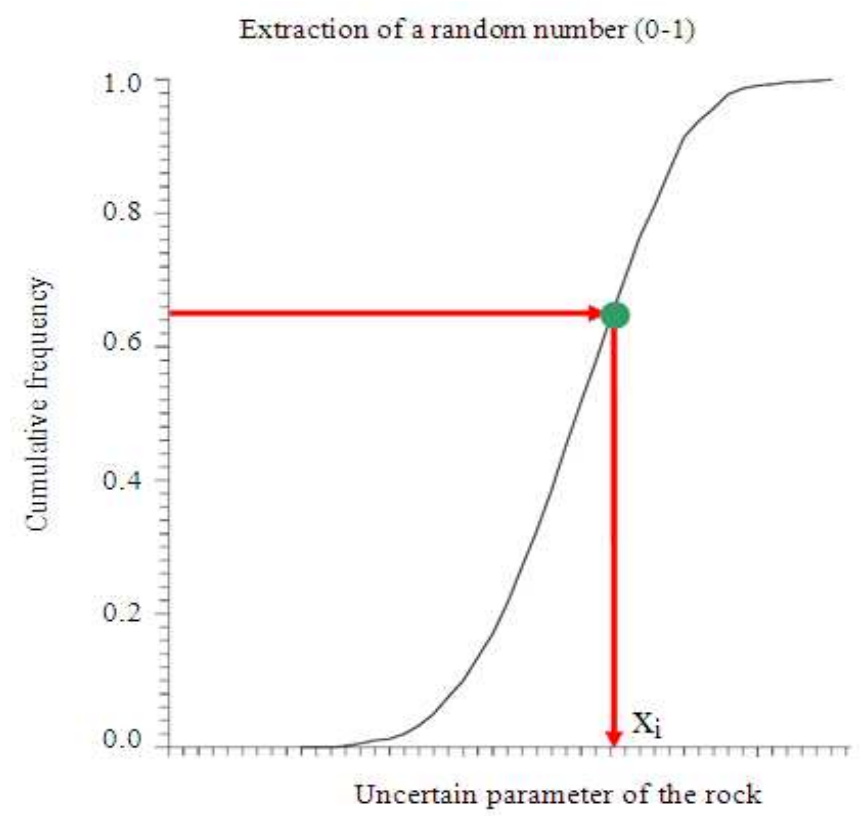

Fig. 9:Determination of the value of an uncertain parameter $\mathrm{x}$ of the rock through the Montecarlo Method. The extraction of a random number between 0 and 1 makes it possible to obtain a value of the uncertain parameter of the rock $\mathrm{x}_{\mathrm{i}}$ on the basis of the knowledge of the cumulative probability distribution

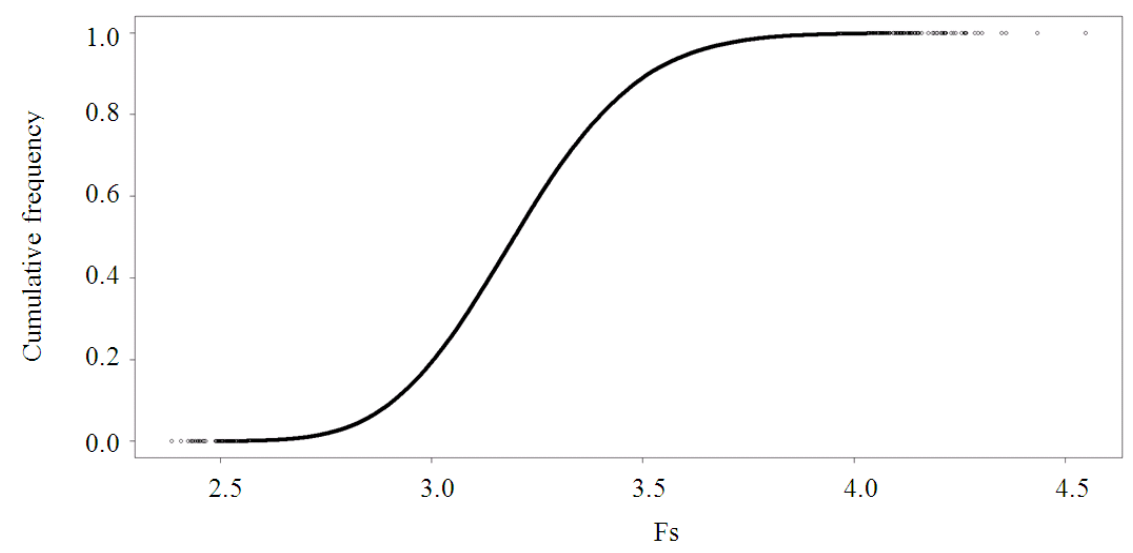

Fig. 10: Cumulative probability distribution of the point safety factor in the rock, at mid-height of the pillar axis $(j=$ 1). The probability of the safety factor being less than 1.05 has been found to be equal to 0 on a sample of 100, 000 safety factor values obtained from an analysis with the Montecarlo Method

From the Hoek and Brown strength criterion, it is possible to see how the strength of the rock mass in a point depends on the GSI, on the $m_{i}$ parameter, on the uniaxial compressive strength of the intact rock $\left(\sigma_{\mathrm{ci}}^{\prime}\right)$, but also on the existing lateral confinement stress (the minor principal stress $\sigma_{3}^{\prime}$ ). The same rock mass shows different values of strength in different internal points of the pillar in function of the lateral confinement stress $\left(\sigma_{3}^{\prime}\right)$ that is present in these points.
Knowing the stress state of a point in the rock mass (inside the rock pillar), it is possible to evaluate the local safety factor through the following simple relation:

$$
\mathrm{F}_{\mathrm{s}}=\frac{\sigma_{1, \mathrm{str}}^{\prime}}{\sigma_{1}^{\prime}}
$$

If the descriptive parameters of the rock are known, through a probabilistic approach (for example, through 
the type of distribution, the mean and the variance), the point safety factor can also be described at a point inside the pillar through a probabilistic distribution.

The simplest way of obtaining the probabilistic distribution of the point safety factors is by referring to the Montecarlo Method.

This method consists in randomly extracting the parameters (on the basis of their individual probabilistic distributions) and selecting a $\mathrm{F}_{\mathrm{s}}$ value that belongs to a gradually increasing sample of data (the calculation is stopped when the statistical tests lead to a stable sample).

The following phases should be followed:

- Calculation of the stress state inside the pillar at several previously identified representative points (for example, the center of each element of the numerical model adopted to analyse the stress state) and in particular the values of the maximum $\left(\sigma_{1, j}^{\prime}\right)$ and minimum $\left(\sigma_{3, \mathrm{j}}^{\prime}\right)$ principal stresses in each reference point $(\mathrm{j})$

- Description of the uncertain parameters of the rock through probabilistic distributions (through the type of distribution and at least the mean and the mean quadratic deviation);

- Calculation of the Cumulative Distribution Function (CDF) for each uncertain parameter, starting from its probabilistic distribution, through numerical integration

- Extraction of a random number between 0 and 1 for each of the uncertain parameters of the rock and from this determination of a value for each uncertain parameter through the CDF (Fig. 9); in the specific case being studied, the extraction of three consecutive random numbers allows three different GSI values $\left(\mathrm{GSI}_{\mathrm{i}}\right)$, the uniaxial compression strength $\sigma_{\mathrm{ci}}\left(\sigma_{\mathrm{ci}, \mathrm{i}}\right)$ and the parameter $\mathrm{m}_{\mathrm{i}}\left(\mathrm{m}_{\mathrm{i}, \mathrm{i}}\right)$ to be obtained

- Evaluation of the point safety factor $\mathrm{F}_{\mathrm{si}, \mathrm{j}}$ at each point $\mathrm{j}$, using the stress state obtained at point a) and the values of the uncertain parameters of the rock obtained at point d)

- Repeatition points d-e until all the $\mathrm{F}_{\mathrm{si}}$ samples referring to the representative point in the pillar are stabilised from the statistic point of view

- Description of the probabilistic distribution of $\mathrm{F}_{\mathrm{si}}$ for each point through the cumulative curve

The application of the procedure to the case history: In the case under study, Gaussian probabilistic distributions (normal) were hypothesised for the three uncertain parameters. The CDFs are therefore calculated, by means of integration, through the following equation:

$$
\mathrm{CDF}_{\mathrm{x}}=\int_{-\infty}^{\mathrm{x}}\left(\frac{1}{\sqrt{2 \cdot \pi} \cdot \sigma_{\mathrm{x}}} \cdot \mathrm{e}^{-\frac{1}{2} \cdot\left(\frac{\mathrm{v}-\mathrm{x}_{\mathrm{m}}}{\sigma_{\mathrm{x}}}\right)^{2}}\right) \cdot d \mathrm{~d}
$$

Where:

$\mathrm{x}=$ The value of the uncertain parameter

$\mathrm{x}_{\mathrm{m}}$ and $\sigma_{\mathrm{x}}=$ The mean and the standard deviation of the uncertain parameter

$\mathrm{v}=$ Ntegration variable

The results of the calculation obtained adopting the above indicated procedure, considering the mean values and the standard deviations reported above for the three uncertain parameters of the rock $\left(\mathrm{GSI}, \sigma_{\mathrm{ci}}, \mathrm{m}_{\mathrm{i}}\right)$, are shown in Fig. 10-12, as examples, in terms of cumulative distribution of the point safety factor in the rock, at three particular mid-height points of the pillar section: on the central axis of the pillar $(j=1)$; at half of its side $(j=2)$ and at the corner $(j=3)$.

From an analysis of the diagrams, such as those reported in Fig. 10-12, it is possible to determine the probability that the point safety factor descends below a pre-fixed value (for example, 1.05) in one or more points inside the pillar.

Should the results not be satisfactory, due to the elevated probability that one or more safety factors are below a pre-fixed value, or because the safety factors are too high, the calculations should be repeated considering different dimensions of the pillar until a final convergence that can be considered acceptable is reached. It is then possible to proceed with the dimensioning of a pillar on the basis of not just one or more deterministic values of the safety factor of the points inside the pillar, but rather on the probabilistic distribution of the safety factors, which are able to point out the reliability of the estimation of the safety factor to the designer in relation to the uncertainty of the initial geomechanical parameters of the rock.

In this way, the designer can make more informed choices (for example, the dimensions of the rock pillars), considering the initial uncertainties of the available data in a more appropriate manner. 
Am. J. Applied Sci., 9 (8): 1273-1282, 2012

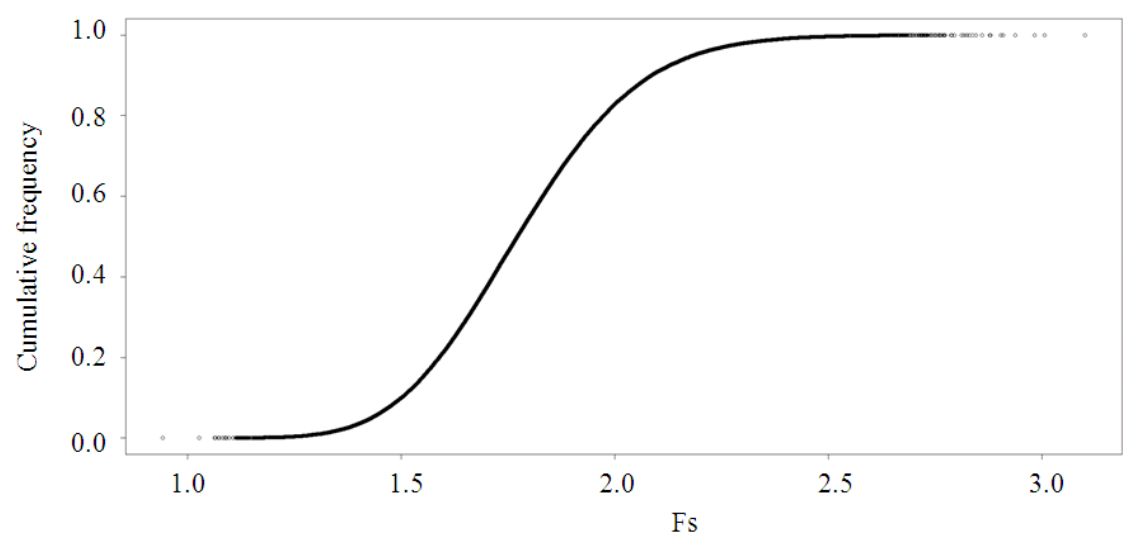

Fig. 11: Cumulative probability distribution of the point safety factor in the rock, at half of the pillar side, in a section at mid-height $(j=2)$. The probability of the safety factor being below 1.05 has been found to be equal to 2 on a sample of 100,000 safety factor values obtained from an analysis with the Montecarlo Method

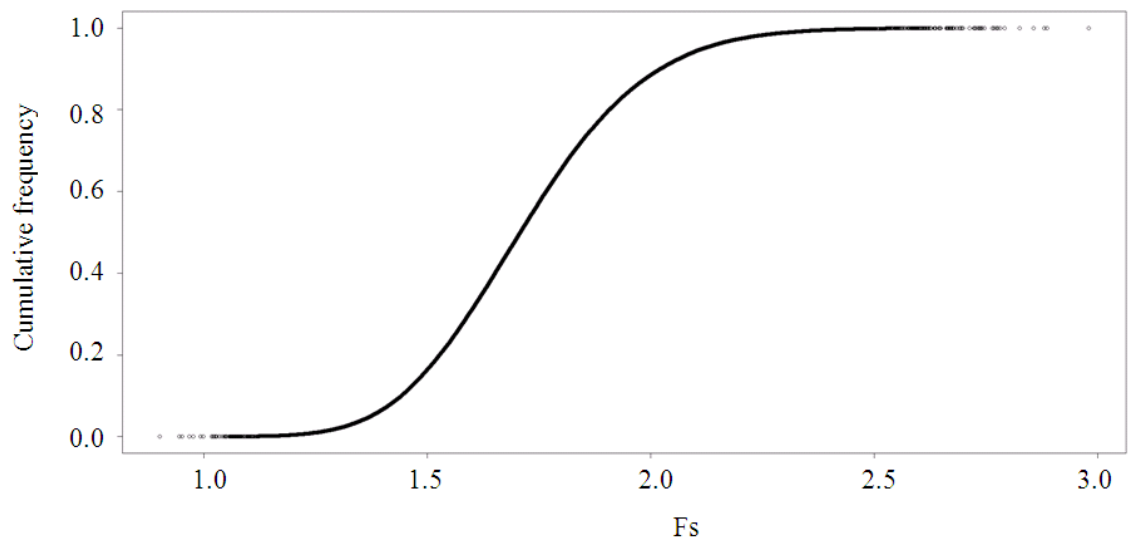

Fig. 12: Cumulative probability distribution of the point safety factor in the rock at a corner, in a mid-height section $(\mathrm{j}=3)$. The probability of the safety factor being below 1.05 has been found to be equal to 5 on a sample of 100,000 safety factor values obtained from an analysis with the Montecarlo Method

\section{CONCLUSION}

The dimensioning of rock pillars in the room and pillar mining method is one of the most interesting problems in rock engineering.

Nowadays, simplified analytical formulations are usually adopted for both the evaluation of the mean axial stress in the pillar and for the evaluation of the pillar strength. The uncertainty concerning the determination of the strength of pillars generally leads to the adoption of high safety factors.

A probabilistic approach for the dimensioning of rock pillars has been proposed in this work. This approach considers the exact development of the stresses inside the pillar and the typical uncertainty of the geomechanical parameters of the rock mass. The approach, which is based on the Montecarlo Method, is able to obtain the cumulative distribution of the point safety factors in one or more points inside the pillar.

Reference has been made to the well known Hoek and Brown strength criterion and the GSI index that describes the frequency and conditions of natural discontinuities in order to obtain the local strength of the rock mass.

Thanks to the proposed approach, it is possible to proceed with the dimensioning of a pillar, not on the basis only of one or more deterministic values of the safety factor in the points inside the pillar, but rather on probabilistic distributions which are able to indicate the reliability of the estimation of the degree of safety to the designer in relation to the uncertainty of the initial geomechnanical parameters of the rock. 


\section{REFERENCES}

A'ssim, A. and Z.Y. Xing, 2010. Most used rock mass classifications for underground opening. Am. J. Eng. Applied Sci., 3: 403-411. DOI: 10.3844/ajeassp.2010.403.411

Cai, M., P.K. Kaiser, H. Uno, Y. Tasaka and M. Minami, 2004. Estimation of rock mass deformation modulus and strength of jointed hard rock masses using the GSI system. Int. J. Rock Mech. Min. Sci., 41: 3-19. DOI: 10.1016/S13651609(03)00025-X

Hoek, E. and E.T. Brown, 1982. Underground Excavations in Rock. 1st Edn., The Institute of Mining and Metallurgy, London, ISBN-10: 0419160302, pp: 536.

Hoek, E. and E.T. Brown, 1997. Practical estimates of rock mass strength. Int. J. Rock Mech. Min. Sci. Geomech. Abstr., 34: 1165-1186. DOI: 10.1016/S1365-1609(97)80069-X

Hoek, E., C. Carranza-Torres and B. Corkum, 2002. Hoek-brown failure criterion-2002 edition. Proceedings of the 5th North American Rock Mechanics Symposium, (NARMC' 02), Toronto, Canada, pp: 267-73.

Huat, B.B.K., 2005. Evaluation of slope assessment system in predicting landslides along roads underlain by granitic formation. Am. J. Eng. Sci., 1: 90-96. DOI: 10.3844/ajessp.2005.90.96
Itasca, 2006. Flac 3D manual.

Jamaludin S., B.B.K. Haut and H. Umar, 2006. Evaluation of slope assessment systems for predicting landslides of cut slopes in granitic and meta-sediment formations. Am. J. Eng. Sci., 2: 135-141. DOI: 10.3844/ajessp.2006.135.141

Oreste, P., 2005a. Back-analysis techniques for the improvement of the understanding of rock in underground constructions. Tunnell. Underground Space Technol., 20: 7-21. DOI: 10.1016/j.tust.2004.04.002

Oreste, P., 2005b. A probabilistic design approach for tunnel supports. Comput. Geotechnics, 32: 520534. DOI: 10.1016/j.compgeo.2005.09.003

Oreste, P., 2006. Correlated probabilistic analysis of the excavation times and costs in tunneling. J. Min. Sci., 42: 269-286. DOI: 10.1007/s10913-006-0055-2

Oreste, P., 2008. Distinct analysis of fully grouted bolts around a circular tunnel considering the congruence of displacements between the bar and the rock. Int. J. Rock Mech. Min. Sci., 45: 10521067.

Sadrnejad, S.A., 2006. Dynamic solution code for structural analysis upon joint element. J. Comput. Sci., 2: 401-409. DOI: 10.3844/jcssp.2006.401.409 